Original Research

\title{
Spatial Distribution, Risk Assessment, and Seasonal Variations of 4-nonylphenol in China's Yinma River Basin
}

\author{
Caiyun Sun ${ }^{1}$, Renshi $\mathrm{Ma}^{3}$, Liang $\mathrm{Xu}{ }^{1 *}$, Libo Chen ${ }^{1 * *}$, Miao Xu${ }^{1}$, \\ Hainan $\mathrm{Cao}^{1}$, Zhenxing Zhang ${ }^{2}$ \\ ${ }^{1}$ School of Resources and Environmental Engineering, Jilin Institute of Chemical Technology, Jilin, China \\ ${ }^{2}$ Institute of Grassland Science, Northeast Normal University and Key Laboratory of Vegetation Ecology, \\ Ministry of Education, Changchun, Jilin, China \\ ${ }^{3}$ Department of Vascular Surgery, First Hospital of Jilin University-Eastern Division, Changchun, \\ Jilin Province, China
}

Received: 24 October 2017

Accepted: 12 February 2018

\begin{abstract}
In recent decades the Yinma River Basin has been receiving increasing pollution from industrial and domestic wastewater, agriculture, and livestock production - which are all potential 4-NP pollution sources. Thus, this work investigated spatial-seasonal distribution, risks, and seasonal variations of 4-nonylphenol in the aquatic environment of the Yinma River Basin. The results indicated that the highest concentrations in water and sediment occurred in livestock-production, industrial, and domestic-wastewater areas, and the lowest occurred in agricultural areas; a seasonal variation in 4-NP concentrations in water was observed, with the highest concentrations occurring in the dry season and the lowest concentrations in the wet season. The results for risk quotient indicated that in three water seasons, low ecological risks of 4-NP in water primarily occurred in agricultural areas, and high ecological risks occurred downstream of domestic-wastewater drainage; the ecological risks of 4-NP in sediment from all the sampling sites were exposed to moderate or high ecological risks. Based on the results for hazard quotient, a seasonal variation in human health risks of 4-NP in water was observed; except for a sampling site located downstream of domestic wastewater drainage, human health risks of 4-NP in water were low.
\end{abstract}

Keywords: 4-nonylphenol, seasonal variations, water, sediment, risk assessment

*e-mail: xlsdydnl@126.com

**e-mail: 2031259758@qq.com 


\section{Introduction}

4-nonylphenol (4-NP) is recognized as one of the major endocrine-disrupting chemicals in the environment. It has been extensively applied in livestock production, agriculture such as pesticide emulsifiers, and industry such as production of surfactants and dyeing auxiliaries [1-2], which can be brought into aquatic environments through runoff, domestic discharge, livestockproduction, and industrial wastewater [3]. 4-NP, with simulating estrogen, can affect living organisms' normal reproduction and growth, and can cause adverse effects on living organisms even at a low concentration [4-5]. Therefore, research on pollution characteristics and risk assessment of 4-NP in aquatic environments have drawn a lot of attention by scientific institutes and environmental protection agencies from all over the world [6].

Water and sediment are important compositions in aquatic environments [7], as 4-NP with a hydroxyl can be dissolved in water, and 4-NP with lipophilicity characteristics has an intendancy of accumulating in the sediment [8]; 4-NP in water can be exposed to aquatic organisms and the human body through ingestion, and 4-NP accumulated in sediment can enter aquatic organisms who prey in the sediment [9]. Due to its toxicity, bioaccumulation and non-degradation, 4-NP can persistently remain in water and sediment, and once the concentrations reach a certain level, it may produce adverse effects on aquatic organisms and human health [10-11]. Additionally, hydrological conditions, river water quantity, and environmental factors [12] can lead to seasonal variations in the concentration and risk levels of 4-NP in an aquatic environment. However, studies on the effects of seasonality on pollution characteristics and risk levels are still limited.

The Yinma River Basin $\left(43^{\circ} 0^{\prime} \mathrm{N}-45^{\circ} 0^{\prime} \mathrm{N}\right.$, $124^{\circ} 30^{\prime} \mathrm{E}-126^{\circ} 0^{\prime} \mathrm{E}$ ), with distinctive water seasons and located in the middle part of Jilin Province of China, receives increasing pollution from livestock production, agriculture, large cities, and industrial and domestic wastewater, which may result in 4-NP pollution in an aquatic environment. However, to our best knowledge, very few studies on the pollution characteristics and risks of 4-NP in an aquatic environment have been reported for this region. Thus, the primary objectives of this work are to investigate spatial-seasonal distribution of 4-NP in water and sediment of the Yinma River Basin; identify possible pollution sources; assess the aquatic ecosystem and human health risks of 4-NP exposure to water and sediment in three water seasons; and illustrate seasonal variations of 4-NP concentration levels and risks.

\section{Material and Methods}

\section{Field Sampling and Pretreatment of Samples}

Yinma River Basin (from $43^{\circ} 0^{\prime} \mathrm{N}$ to $45^{\circ} 0^{\prime} \mathrm{N}$ and from $124^{\circ} 30^{\prime} \mathrm{E}$ to $126^{\circ} 0^{\prime} \mathrm{E}$ ) is located in the middle of Jilin Province of China, which is the primary water sourc for domestic water supply and irrigation of farmlands.
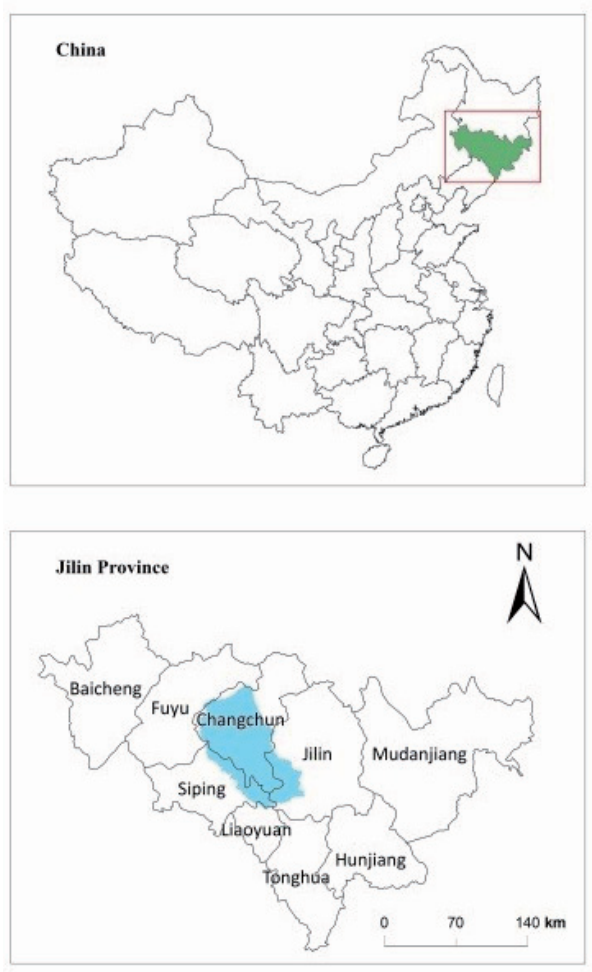

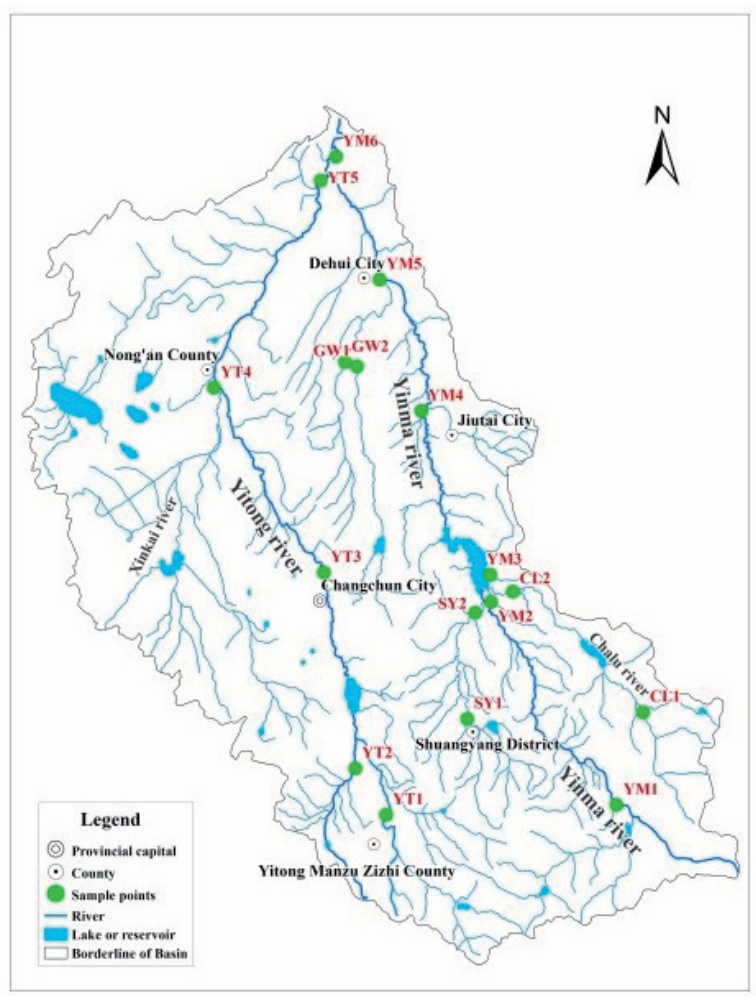

Fig. 1. Locations of Yinma River Basin and sampling sites. 
Seventeen monitoring sections covering all the basin are set up by local authorities (as shown in Fig. 1). The samples were collected from sampling sites located downstream of domestic-wastewater drainage (YM1), livestock-production areas (YM2 and YT4), and downstream of sewage treatment plant drainage in Changchun (SY1), and the other samples were collected from the sampling sites located in agricultural and rural areas. Based on the hydrological characteristics in the Yinma Basin, May, August, and November are respectively normal, wet, and dry seasons. To study spatial and seasonal variations, in May, August, and November 2016, sampling campaigns were performed in 17 monitoring sections.

Each sample was thoroughly mixed with three subsamples, and the distance of every two subsamples was far from $100 \mathrm{~m}$. The water samples $(10 \mathrm{~L})$ were collected from surface water (below 0-0.5 m), filtered with $0.45 \mu \mathrm{m}$ glass fiber filters, separately stored in brown glasses, and transported to lab for analyses within $24 \mathrm{~h}$. The sediment samples $(0-0.5 \mathrm{~m})$ were taken with an iron grab sampler and dried in the dark, ground in a mortar, passed through a 100-mesh sieve, and analyzed immediately (dry weight).

\section{Analysis Methods}

The methods were followed as a published article [13].

\section{Extraction Methods}

$1 \mathrm{~L}$ of each water sample (pre-adjusted to $\mathrm{pH} 3.0$ with $\mathrm{H}_{2} \mathrm{SO}_{4}$ ) was passed through an HLB cartridge (Waters Oasis) which was pre-conditioned with $2 \mathrm{~mL}$ of methanol and $2 \mathrm{~mL}$ of distilled water. The target compound was eluted with $7 \mathrm{~mL}$ of methanol and $5 \mathrm{~mL}$ of dichloromethane successively, then elutes were reduced to near dryness by a rotary vacuum evaporation apparatus (RE-52AA, Shanghai Yarong Inc., China), and dissolved in $1 \mathrm{~mL}$ of methanol for derivatization.

Each sediment sample (5 g) was extracted in an ultrasonic bath with $10 \mathrm{~mL}$ of ethyl acetate for $15 \mathrm{~min}$. After centrifuging at $1370 \mathrm{~g}$ for $15 \mathrm{~min}$, the extracts were collected. The extraction process was repeated three times, and the extracts from three extraction processes were thoroughly mixed. The mixed extracts were reduced to near dryness by a rotary vacuum evaporation apparatus, dissolved in $1 \mathrm{~mL}$ of methanol, and passed through a silica gel $(1 \mathrm{~g})$ column. Then the column was successively eluted with $6 \mathrm{~mL}$ of $\mathrm{n}$-hexane, $6 \mathrm{~mL}$ of ethyl acetate, and $6 \mathrm{~mL}$ of methanol, and the elutes were reduced to near dryness by a rotary vacuum evaporation apparatus, and dissolved in $1 \mathrm{~mL}$ of methanol for derivatization.

\section{Derivatization Method}

The elutes were derivatized with MSTFA at $70^{\circ} \mathrm{C}$ for $2 \mathrm{~h}$, cooled to room temperature, and reduced to near dryness by a rotary vacuum evaporation apparatus. Then $1 \mu \mathrm{L}$ was injected for quantification.

\section{Quantification Methods}

The concentrations of 4-NP in water and sediment samples were quantified with a gas chromatograph-mass spectrometer (GC-MS). The injection port was held at $300^{\circ} \mathrm{C}$, and the injection volume was $1 \mu \mathrm{L}$. Helium (99.999\%) was used as a carrier gas with the column flow rate of $1 \mathrm{~mL} / \mathrm{min}$. The column temperature was risen from $80^{\circ} \mathrm{C}$ to $220^{\circ} \mathrm{C}$ at a rate of $10^{\circ} \mathrm{C} / \mathrm{min}$, from $220^{\circ} \mathrm{C}$ to $260^{\circ} \mathrm{C}$ at a rate of $4^{\circ} \mathrm{C} / \mathrm{min}$, and from $260^{\circ} \mathrm{C}$ to $300^{\circ} \mathrm{C}$ at a rate of $5^{\circ} \mathrm{C} / \mathrm{min}$, finally rising to $310^{\circ} \mathrm{C}$ at a rate of $20^{\circ} \mathrm{C} / \mathrm{min}$. MS interface temperature was held at $310^{\circ} \mathrm{C}$. Negative chemical ionization mode was employed, and methane (purity $>99.999 \%$ ) was used as the reaction gas at a rate of $2.0 \mathrm{~mL} / \mathrm{min}$. The ion source and quadrupole temperatures were both held at $150^{\circ} \mathrm{C}$.

\section{Quality Assurance}

All the data were subjected to strict quality assurance. The standard solutions of 4-NP were used to conduct method validation and quality assurance with correlation coefficients for calibration curves higher than 0.995. All the experiments were conducted in duplicate with relative standard deviations lower than $15 \%$. Five parallel experiments of recovery efficiencies for water and sediment samples from three water seasons were respectively checked by spiking samples with standard solutions. The results showed that the recovery rates for water samples from three water seasons were all within $80-105 \%$, and for sediment samples from three water seasons were all within 70-95\%. The detection limits for water samples from three water seasons were all below $5 \mathrm{ng} / \mathrm{L}$, and for sediment samples from three water seasons were all below $10 \mathrm{ng} / \mathrm{g}$.

\section{Ecological Risk Assessment}

Aquatic ecosystem risks of 4-NP were assessed with risk quotient (RQ), which are calculated with the following equation (1):

$$
\mathrm{RQ}=\mathrm{MC} / \mathrm{PNEC}
$$

...where $\mathrm{MC}$ is the monitoring concentration, and PNEC is the predicted no-effect concentration for 4-NP; PNECs were adopted as $330 \mathrm{ng} / \mathrm{L}$ in water and $39 \mathrm{ng} / \mathrm{g}$ in sediment [14] (EU, 2002).

$\mathrm{RQ}>1$ is regarded as a high risk; $0.1<\mathrm{RQ}<1$ is regarded as a moderate risk; and $\mathrm{RQ}<0.1$ is regarded as a low risk [15].

\section{Health Risk Assessment}

As the Yinma River Basin is the primary water source for domestic water supply and irrigation of 
Table 1. Basic statistical data for 4-NP concentrations in water (ng/L) and sediment (ng/g) for three water seasons.

\begin{tabular}{|c|c|c|c|c|c|c|c|}
\hline Water & Normal season & Wet season & Dry season & Sediment & Normal season & Wet season & Dry season \\
\hline YM1 & 331.35 & 244.00 & 392.41 & YM1 & 87.00 & 45.82 & 89.74 \\
\hline YM2 & 113.84 & 62.99 & 130.09 & YM2 & 35.97 & 30.78 & 44.46 \\
\hline YM3 & 34.66 & 41.97 & 23.33 & YM3 & 13.57 & 26.33 & 19.78 \\
\hline YM4 & 39.12 & 27.13 & 44.81 & YM4 & 10.42 & 14.86 & 26.25 \\
\hline YM5 & 58.08 & 46.66 & 70.73 & YM5 & 10.31 & 7.94 & 13.30 \\
\hline YM6 & 50.63 & 44.09 & 56.15 & YM6 & 16.93 & 13.58 & 23.05 \\
\hline YT1 & 23.39 & 16.32 & 29.86 & YT1 & 25.12 & 33.42 & 35.74 \\
\hline YT2 & 15.27 & 20.62 & 29.11 & YT2 & 9.89 & 17.89 & 13.68 \\
\hline YT3 & 75.11 & 64.82 & 99.76 & YT3 & 51.62 & 45.96 & 45.94 \\
\hline YT4 & 102.94 & 81.21 & 97.38 & YT4 & 25.36 & 19.85 & 28.07 \\
\hline YT5 & 31.49 & 14.32 & 34.61 & YT5 & 20.09 & 31.58 & 46.79 \\
\hline SY1 & 168.14 & 141.76 & 192.45 & SY1 & 85.01 & 98.44 & 89.29 \\
\hline SY2 & 32.73 & 33.70 & 49.69 & SY2 & 25.97 & 13.04 & 22.11 \\
\hline CL1 & 64.37 & 47.79 & 58.42 & CL1 & 18.48 & 10.00 & 22.68 \\
\hline CL2 & 42.87 & 17.97 & 48.64 & CL2 & 22.07 & 24.23 & 28.29 \\
\hline GW1 & 24.62 & 14.13 & 28.05 & GW1 & 26.61 & 20.78 & 22.67 \\
\hline WK1 & 49.53 & 35.45 & 61.81 & WK1 & 18.88 & 19.31 & 15.93 \\
\hline Max & 331.35 & 244.00 & 392.41 & Max & 87.00 & 98.44 & 89.74 \\
\hline Min & 15.27 & 14.13 & 23.33 & Min & 9.89 & 7.94 & 13.30 \\
\hline Median & 49.53 & 41.97 & 56.15 & Median & 22.07 & 20.78 & 26.25 \\
\hline Mean & 74.01 & 56.17 & 85.13 & Mean & 29.60 & 27.87 & 34.57 \\
\hline
\end{tabular}

farmlands, the exposure of pollutants to water may pose a risk to human health. Thus, in this study, the estimated dietary intake (EDI, ng/kg bw/day) was employed to assess the human health risks of 4-NP exposure to water from Yinma Basin, and the values of EDI were calculated with the following equation [16]:

$$
\mathrm{EDI}=(\mathrm{MC} \times \mathrm{a}) / \mathrm{BW}
$$

...where a is the quantity of water (L/day) consumed daily and BW is the body weight. Daily water intake is $1.4 \mathrm{~L} /$ day for adults, and the average weight of an adult is $60 \mathrm{~kg}$ [17].

The intakes of 4-NP though food chains is considered as a chronic impact on human health. The hazard quotient (HQ) was employed to assess the potential human health risks, and calculated with the following equation [17]:

$$
\mathrm{HQ}=\mathrm{EDI} / \mathrm{RfD}
$$

...where RfD is the reference dose, which is the tolerable daily intake (TDI). The TDI of 4-NP is $5 \mathrm{ng} / \mathrm{g}$ bw/day based on the Danish Environmental Agency [18].
$\mathrm{HQ}>1$ indicates the existence of a high potential human health risk, while $\mathrm{HQ}<1$ indicates the existence of a low potential human health risk.

\section{Results and Discussion}

\section{Levels Concentrations in Water and Sediment}

The basic statistics analyses were conducted for 4-NP concentrations in water and sediment samples from 17 sampling sites respectively located in industrial, agricultural, livestock-production, urban, and rural areas. Table 1 shows that 4-NP concentrations in water samples varied from $15.27 \mathrm{ng} / \mathrm{L}$ to $331.35 \mathrm{ng} / \mathrm{L}$ with mean and median values of $74.01 \mathrm{ng} / \mathrm{L}$ and $49.53 \mathrm{ng} / \mathrm{L}$ in the normal season, from $14.13 \mathrm{ng} / \mathrm{L}$ to $244 \mathrm{ng} / \mathrm{L}$ with mean and median values of $56.17 \mathrm{ng} / \mathrm{L}$ and $41.97 \mathrm{ng} / \mathrm{L}$ in the wet season, and from $23.33 \mathrm{ng} / \mathrm{L}$ to $392.41 \mathrm{ng} / \mathrm{L}$ with mean and median values of $85.13 \mathrm{ng} / \mathrm{L}$ and $56.15 \mathrm{ng} / \mathrm{L}$ in the dry season; 4-NP concentrations in sediment samples varied from $9.89 \mathrm{ng} / \mathrm{g}$ to $87 \mathrm{ng} / \mathrm{g}$ with mean and median values of $29.6 \mathrm{ng} / \mathrm{g}$ and $22.07 \mathrm{ng} / \mathrm{g}$ in the normal season, from $7.94 \mathrm{ng} / \mathrm{g}$ to $98.44 \mathrm{ng} / \mathrm{g}$ with mean and median 
values of $27.87 \mathrm{ng} / \mathrm{g}$ and $20.78 \mathrm{ng} / \mathrm{g}$ in the wet season, and from $13.3 \mathrm{ng} / \mathrm{g}$ to $89.74 \mathrm{ng} / \mathrm{g}$ with mean and median values of $34.57 \mathrm{ng} / \mathrm{g}$ and $26.25 \mathrm{ng} / \mathrm{g}$ in the dry season. The mean concentrations of 4-NP for three water seasons were $71.77 \mathrm{ng} / \mathrm{L}$ for water and $30.68 \mathrm{ng} / \mathrm{g}$ for sediment.

To evaluate 4-NP contamination levels of Yinma Basin, the obtained data were used to compare with the PNECs (330 ng/L for water and $39 \mathrm{ng} / \mathrm{g}$ for sediment). In three water seasons, the mean and median concentrations in water were all below the PNEC, and the mean and median concentrations in sediment were all below the PNEC. These results suggest that 4-NP pollution in the aquatic environment of Yinma Basin were at a low level, but the exposure risks of 4-NP to water and sediment on the aquatic ecosystem and human health should be further evaluated.

\section{Spatial-Seasonal Distribution and Pollution Sources of 4-NP in Water}

Yinma Basin has been receiving pollution from urban and rural areas, agriculture, livestock-production, industrial, and domestic wastewater. In order to evaluate the contributions of theses contamination sources, the concentrations of 4-P in the water and sediment samples collected from urban, rural, agricultural, industrial, and livestock-production areas were compared.

The spatial-seasonal distribution of 4-NP in water is illustrated in Fig. 2. In normal season, the highest concentration with a value of $331.35 \mathrm{ng} / \mathrm{L}$ was found downstream of domestic-wastewater drainage (YM1), which was beyond the PNEC (330 ng/L), and followed by SY1 with a value of $168.14 \mathrm{ng} / \mathrm{L}$; middle concentrations occurred at YM2 and YT4; the lower concentrations in all the other sampling sites were all below $100 \mathrm{ng} / \mathrm{L}$. In wet season, the highest concentration with a value of $244 \mathrm{ng} / \mathrm{L}$ occurred downstream of domesticwastewater drainage (YM1), followed by SY1 with a value of $141.76 \mathrm{ng} / \mathrm{L}$, which is much lower than

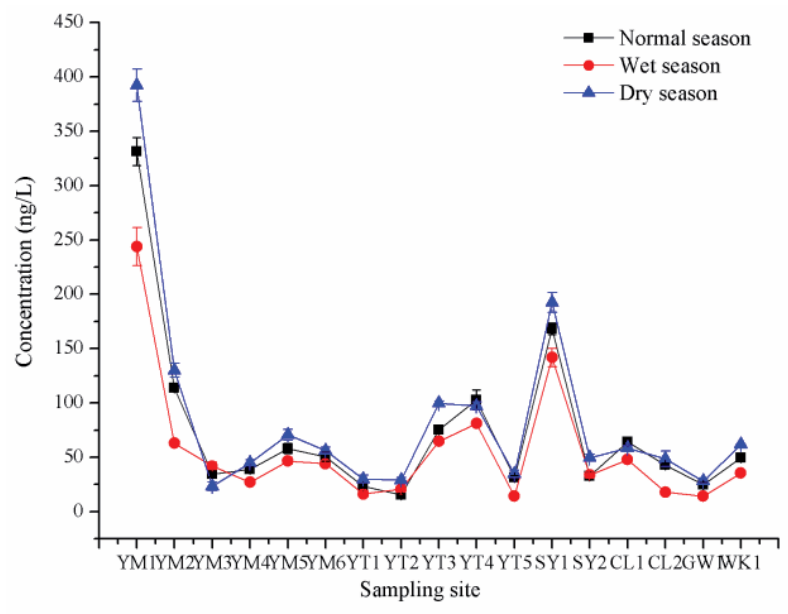

Fig. 2. Spatial-seasonal distribution of 4-NP in water of Yinma River Basin. the highest concentration; concentrations in all the other sampling sites were all below $100 \mathrm{ng} / \mathrm{L}$. In dry season, the highest value of concentration in YM1 was $392.41 \mathrm{ng} / \mathrm{L}$, which was beyond the PNEC; the following highest concentrations with a value higher than $100 \mathrm{ng} / \mathrm{L}$ were found at SY1 and YM2; the concentrations in all the other sampling sites were all below the PNEC.

Obviously, locations with elevated 4-NP concentration levels primarily came from industrial and domestic wastewater. 4-NP existing in household products such as personal care products and detergents for washing clothes and dishes can be gathered in domestic wastewater [19], the domestic wastewater being with a high 4-NP concentration level. Nevertheless, domestic wastewater discharges into the sampling site (YM1) and is regarded as a primary source for 4-NP pollution in an aquatic environment. Also, 4-NP has been extensively applied for industrial production [2], but 4-NP gathering in wastewater is not designed to be removed by the wastewater treatment plants, resulting in increasing 4-NP concentrations in water. The next higher concentrations all occurred in livestock-production areas (YM2 and YT4), and in Changchun City with a developed industry and a large population (YT3). Not obvious 4-NP pollution sources were observed in agricultural and rural areas.

\section{Spatial-Seasonal Distribution and Pollution Sources of 4-NP in Sediment}

Fig. 3 illustrates spatial and seasonal distribution of 4-NP in sediment of Yinma River Basin. In normal season, the highest concentrations were found at YM1 with a value of $87 \mathrm{ng} / \mathrm{g}$ and SY1 with a value of $85 \mathrm{ng} / \mathrm{g}$, and followed by YT3 with a value of $51.62 \mathrm{ng} / \mathrm{g}$, which are all beyond the PNEC (39 ng/g); middle concentrations occurred at YM2, YT1, YT4, YT5, SY2, CL2, and GW1; the low concentrations with a value lower than $20 \mathrm{ng} / \mathrm{g}$ occurred at all the other sampling sites. In the wet season, the highest concentration

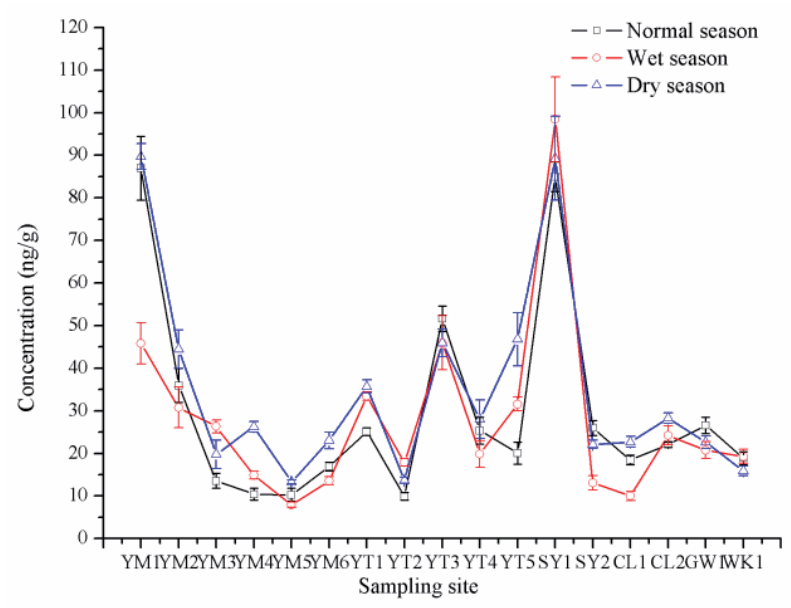

Fig. 3. Spatial-seasonal distribution of 4-NP in sediment of Yinma River Basin. 
occurred at SY1 with a value of $98.44 \mathrm{ng} / \mathrm{g}$, which is two times higher than at YM1 $(45.82 \mathrm{ng} / \mathrm{g})$ and YT3 $(45.96 \mathrm{ng} / \mathrm{g})$; the middle concentrations occurred at YM2, YM3, YT1, YT5, CL2, and GW1; the low concentrations occurred at all the other sampling sites with a value lower than $20 \mathrm{ng} / \mathrm{g}$. In dry season, the highest concentrations occurred at YM1 with a value of $89.74 \mathrm{ng} / \mathrm{g}$ and SY1 with a value of $89.29 \mathrm{ng} / \mathrm{g}$, followed by YM2, YT3 and YT5 with a value higher than $44 \mathrm{ng} / \mathrm{g}$. Except for YM3, YM5, YT2, and WK1 (with a value lower than $20 \mathrm{ng} / \mathrm{g}$ ), the concentrations in all the other sampling sites were within $20-35 \mathrm{ng} / \mathrm{g}$.

Sediment is considered to be a reservoir of pollutants, and a good indicator for a pollutant's long-term accumulation records [11]. The concentration levels of 4-NP in sediment are not exactly consistent with the concentration levels in water, which may be due to the degree of varied accumulating organic pollutants, as the interference of inorganic matrix and variation of dissolve organic carbon contents in different sampling sites [20]. Locations with the highest concentration levels receive domestic and wastewater treatment plant wastewater (YM1 and SY1), and pollution from the developed city (YT3). Not obvious 4-NP pollution sources were observed in other areas.

\section{Seasonal Variations}

Seasonal variations may influence the presence of organic pollutants in an aquatic environment by leading to changes in river water quantity and environmental factors affecting organic pollutants' natural attenuation, such as sediment sorption and desorption, photodegradation, and biodegradation.

Yinma Basin, with three distinctive water seasons, may lead to a seasonal variation in 4-NP concentration levels in an aquatic environment. As shown in Fig. 2, concentrations of 4-NP in water were influenced by hydrological conditions and represented a seasonal variation, the highest mean concentration of 4-NP in water occurred in the dry season, while the lowest mean concentration occurred in the wet season.

On average, the highest 4-NP concentration in sediment occurred in the dry season, and the lowest occurred in the wet season. In Fig. 3, it can be seen that 4-NP concentrations in sediment did not show a seasonal variation, as the influences of hydrological conditions on 4-NP concentrations in sediment were not great.

\section{Risk Assessment}

\section{Ecological Risk Assessment}

Fig. 4 represents the values of RQ for 4-NP in water from 17 sampling sites. In normal season, the values of RQ for YM1 were higher than 1, except for YT1 and YT2 with a value of lower than 0.1, the values of RQ for the other sampling sites were in the range of 0.1-1. In

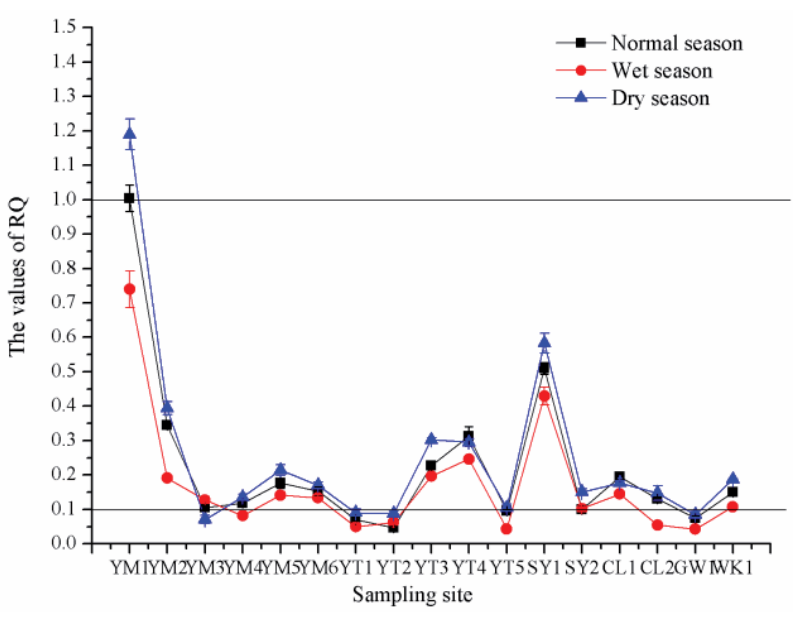

Fig. 4. Values of RQ for 4-NP in water from 17 sampling sites.

wet season, the values of RQ for all the sampling sites were below 1, except for YM4, YT1, YT2, YT5, CL2, and GW1 with values lower than 0.1 , the values for other sampling sites were in the range of 0.1-1. In the dry season, except for YM1 with a value of higher than 1, the values of RQ for all the sampling sites were below 1, the values for YM3, YT1, YT2 and GW1 were below 0.1, and the values for other sampling sites were in the range of 0.1-1.

Fig. 4 shows that ecological risk levels were represented as seasonal variations, with the highest risk levels occurring in the dry season while the lowest risk levels occurred in the wet season. Among 17 sampling sites, in three water seasons the highest ecological risks all occurred downstream of domestic-wastewater drainage (YM1), indicating that domestic wastewater increased ecological risks. In normal and dry seasons, except for YT1, YT2, and GW1 with low ecological risk, the other sampling sites were exposed to a moderate risk; in the wet season, the locations of YM4, YT1, YT2, YT5, CL2, and GW1 were exposed to a low ecological risk, and the other sampling sites were exposed to

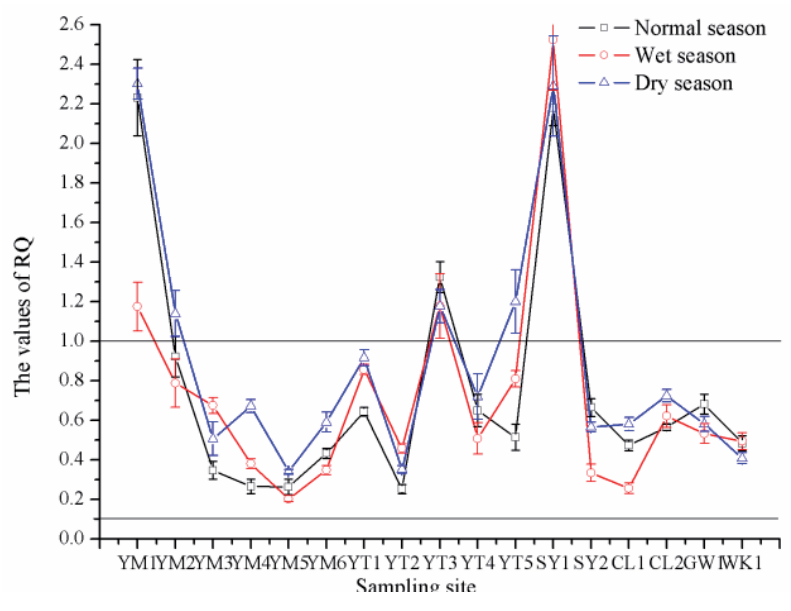

Fig. 5. Values of RQ for 4-NP in sediment from 17 sampling sites. 


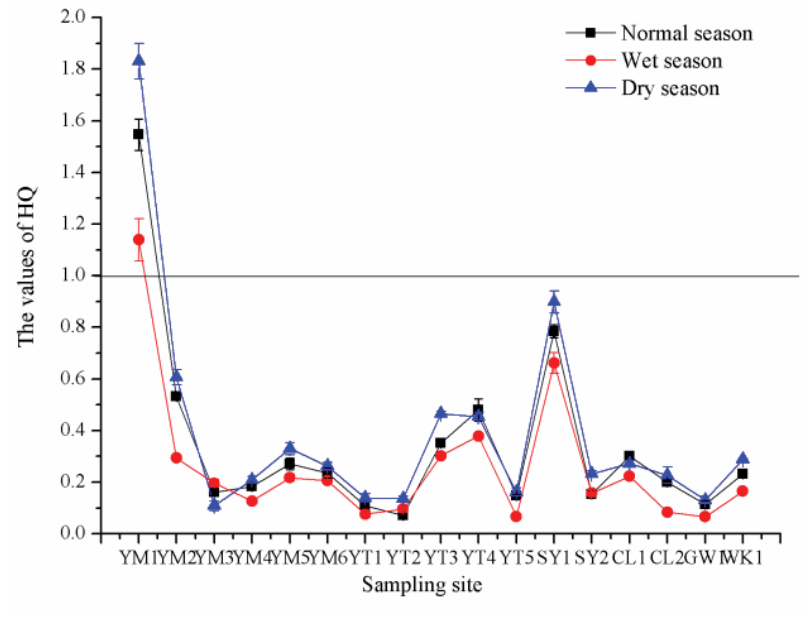

Fig. 6. Values of HQ for 4-NP in water from 17 sampling sites.

a moderate ecological risk. Based on the results for RQ, the low ecological risks primarily occurred in agricultural areas (YT1, YT2, and GW1), and downstream of sewage treatment plant drainage (SY1) and livestockproduction areas (YM2 and YT4) were exposed to a moderate risk.

Fig. 5 represents the values of RQ for 4-NP in sediment from 17 sampling sites. In normal season, the values of RQ for YM1, YT3, and SY1 were higher than 1 , and the values of RQ for the other sampling sites were in the range of 0.1-1. In wet season, except for YM1, YT3 and SY1 with a value of higher than 1, the values for the other sampling sites were in the range of 0.1-1. In dry season, the values of RQ for YM1, YM2, YT3, YT5, and SY1 were higher than 1, the values for the other sampling sites were in the range of 0.1-1.

In Fig. 5 we can see that risks levels of 4-NP in sediment were not represented as obvious seasonal variations. In three water seasons, 17 sampling sites were all exposed to a moderate or high ecological risk. In three water seasons, the highest ecological risk levels all occurred in locations receiving pollution from industrial and domestic wastewater, and developed city (YM1, YT3, and SY1). In dry season, YM2 and YT5 were exposed to a high ecological risk; and all the other sampling sites were exposed to a moderate risk in three water seasons.

\section{Health Risk Assessment}

Because Yinma Basin is a primary source for domestic water supply, it is necessary to evaluate human health risks of 4-NP in water. Fig. 6 illustrates the values of HQ for 4-NP in water from 17 sampling sites. In three water seasons, except for YM1 with a value of higher than 1, the values of HQ for the other sampling sites were all lower than 1 . The results indicated that among three water seasons, the exposure risks of 4-NP to human health represented a seasonal variation; the human health risks were the highest in the dry season and the lowest in the wet season, with human health risk levels being consistent with the concentration levels of 4-NP in water. In three water seasons, except for YM1, the exposure risks of 4-NP in water on human health were all low. It is not surprising that the exposure risks of 4-NP in water sample (YM1) on human health was high, as the water sample (YM1) was collected downstream from domestic-wastewater drainage.

\section{Conclusions}

This work mainly investigated spatial-seasonal distribution, potential pollution sources, and risks of 4-nonylphenol in water and sediment of Yinma River Basin. The results indicated that 4-NP concentrations in water and sediment were both at a low level; the highest concentrations in water and sediment occurred in livestock-production, industrial and domesticwastewater areas, and the lowest occurred in agricultural areas, suggesting that potential pollution sources for 4-NP in water and sediment were livestock production, and industrial and domestic wastewater; in three water seasons, the highest mean concentrations in water and sediment occurred in the dry season, and the lowest mean concentrations both occurred in the wet season. The results for risk quotient indicated that low ecological risks of 4-NP in water primarily occurred in agricultural areas, and high ecological risks occurred downstream of domestic-wastewater drainage; the ecological risks of 4-NP in sediment from all the sampling sites were regarded as a moderate or a high ecological risk. Based on the results for hazard quotient, except for YM1 located downstream from domestic-wastewater drainage, the human health risks of 4-NP in water of all the sampling sites were low.

\section{Acknowledgements}

This work was supported by the National Natural Science Foundation of China under grant No. 51708248, the Startup Foundation for Doctoral Talents by Jilin Institute of Chemical Technology (No. 2018[001]), as a Major Project of Jilin Institute of Chemical Technology under grant No. 2015004, the National Natural Science Foundation of China under grant No. 51708248, and the National Natural Science Foundation of China under grant No. 41501566. We want to thank the Institute of Grassland Science, Northeast Normal University, and Key Laboratory of Vegetation Ecology, Ministry of Education for their financial and technical support.

\section{Conflict of Interest}

The authors declare no conflict of interest. 


\section{References}

1. DIAMANTI-KANDARAKIS E. Endocrine-disrupting chemicals: an endocrine society scientific statement. Endocr. Rev. 30, 293, 2009

2. XIANG-LI L.I., LUAN T.G., YAN L., WONG M.H., LAN C.Y. Distribution patterns of octylphenol and nonylphenol in the aquatic system at Mai Po Marshes nature reserve, a subtropical estuarine wetland in Hong Kong. J. Environ. Sci. 19, 657, 2007.

3. DE-GARCIA S.A.O., PINTO G.P., GARCIA-ENCINA P.A., IRUSTA-MATA R. Ecotoxicity and environmental risk assessment of pharmaceuticals and personal care products in aquatic environments and wastewater treatment plants. Ecotoxicol. 23 (8), 1517, 2014.

4. GAW S., THOMAS K.V., HUTCHINSON T.H. Sources, impacts and trends of pharmaceuticals in the marine and coastal environment. Philos. Trans. R. Soc. B. 369 (1656), 20130572,2014

5. KABIR E.R., RAHMAN M.S., RAHMAN I. A review on endocrine disruptors and their possible impacts on human health. Environ. Toxicol. Pharmacol. 40, 241, 2015.

6. SANTOS L., ARAUJO A.N., FACHINI A., PENA A., DELERUE-MATOS C., MONTENEGRO M. Ecotoxicological aspects related to the presence of pharmaceuticals in the aquatic environment. J. Hazard. Mater. 175 (1-3), 45, 2010.

7. SUN C.Y., ZHANG J.Q., MA Q.Y., CHEN Y.N., JU H.Y. Polycyclic aromatic hydrocarbons (PAHs) in water and sediment from a river basin: sediment-water partitioning, source identification and environmental health risk assessment. Environ. Geochem. Heal. 39 (1), 63, 2017.

8. SUN C.Y., ZHANG J.Q., MA Q.Y., ZHANG F., CHEN Y.N. Risk assessment of polycyclic aromatic hydrocarbons (PAHs) in sediments from a mixed-use reservoir. Human and Ecological Risk Assessment: An International Journal. 22 (2), 447, 2017

9. FEI Y.H., XING B.S., LI X.Y. Changes in the adsorption of bisphenol A, 17a-ethinyl estradiol, and phenanthrene on marine sediment in Hong Kong in relation to the simulated sediment organic matter decomposition. Environ. Pollut. 192, 139, 2014.

10. STANISZEWSKA M., FALKOWSKA L., GRABOWSKI P., KWASNIAK J., MUDRAK-CEGIOLKA S., REINDL A.R. Bisphenol A, 4-tert-octylphenol, and 4-nonylphenol in the Gulf of Gdansk (southern Baltic). Arch. Environ. Contam. Toxicol. 67, 335, 2014
11. ISOBE T., NISHIYAMA H., NAKASHIMA A., TAKADA H. Distribution and behavior of nonylphenol, octylphenol, and nonylphenol monoethoxylate in Tokyo metropolitan area: their association with aquatic particles and sedimentary distributions. Environ. Sc. Technol. 35, 1041, 2001.

12. SUN C.Y., MA Q.Y., ZHANG J.Q., ZHOU M., CHEN Y.N. Predicting seasonal fate of phenanthrene in aquatic environment with a Markov chain. Environm. Sci. Pollut. Res. 23 (16), 16661, 2016.

13. ROCHA J.M., CRUZEIRO C., REIS M., ROCHA E., PARDAL M. Determination of seventeen endocrine disruptor compounds and their spatial and seasonal distribution in Ria Formosa Lagoon (Portugal). Environ. Monit. Assess. 185, 8215, 2013.

14. EU, 2002. European Union Risk Assessment Report 4-nonylphenol (Branched) and Nonylphenol.

15. BLAIR B.D., CRAGO J.P., HEDMAN C.J., KLAPER R.D. Pharmaceuticals and personal care products found in the Great Lakes above concentrations of environmental concern. Chemosphere 93, 2116, 2013.

16. HE D., YE X., XIAO Y., ZHAO N., LONG J., ZHANG P. Dietary exposure to endocrine disrupting chemicals in metropolitan population from China: a risk assessment based on probabilistic approach. Chemosphere 139, 2, 2015.

17. SALGUEIRO-GONZALEZ N., TURNES-CAROU I., BESADA V., MUNIATEGUI-LORENZO S., LOPEZMAHIA P., PRADA-RODRIGUEZ D. Occurrence, distribution and bioaccumulation of endocrine disrupting compounds in water, sediment and biota samples from a European river basin. Sci. Total Environ. 529, 121, 2015.

18. BRADLEY E.L. 2010. Nonylphenol in food contact plastics and migration into foods. http://www.food.gov.uk/science/ research/chemical-saftey-research/a03057(accessed 01. 05. 2017).

19. ROSI-MARSHALL E.J., ROYER T.V. Pharmaceutical compounds and ecosystem function: an emerging research challenge for aquatic ecologists. Ecosystems 15 (6), 867, 2012.

20. GUO W., HE M.C., YANG Z.F., LIN C., QUAN X., MEN B. Distribution, partitioning and sources of polycyclic aromatic hydrocarbons in Daliao River water system in dry season, China. J Hazard Mater, 164, 1379, 2009. 